DOI: 10.1002/adsc.200800555

\title{
New Simple Hydrophobic Proline Derivatives as Highly Active and Stereoselective Catalysts for the Direct Asymmetric Aldol Reaction in Aqueous Medium
}

\author{
Francesco Giacalone, ${ }^{a}$ Michelangelo Gruttadauria, ${ }^{\mathrm{a}, *}$ Paolo Lo Meo, ${ }^{\mathrm{a}}$ \\ Serena Riela, ${ }^{\mathrm{a}}$ and Renato Noto $^{\mathrm{a}}$ \\ a Dipartimento di Chimica Organica "E. Paternò”, Università di Palermo, Viale delle Scienze, Pad. 17, 90128, Palermo, \\ Italy \\ Fax: (+39)-091-596-825; e-mail: mgrutt@unipa.it
}

Received: September 10, 2008; Revised: October 20, 2008; Published online: November 17, 2008

\begin{abstract}
New 4-substituted acyloxyproline derivatives with different hydrophobic properties of the acyl group were easily synthesized and used as catalysts in the direct asymmetric aldol reaction between cyclic ketones (cyclohexanone and cyclopentanone) and several substituted benzaldehydes. Reactions were carried out using water, this being the best reaction medium examined. Screening of these catalysts showed that compounds bearing the most hydrophobic acyl chains [4-phenylbutanoate and 4(pyren-1-yl)butanoate] provided better results. The latter catalysts were successfully used in only 2
\end{abstract}

$\mathrm{mol} \%$ at room temperature without additives to give aldol products in excellent stereoselectivities. These results demonstrate that derivatization of the proline moiety with the proper simple hydrophobic substituent in the 4-position can furnish highly active and stereoselective catalysts without the need of additional chiral backbones in the molecule. Finally, an explanation of the observed stereoselectivities in the presence of water is provided.

Keywords: aldehydes; aldol reaction; ketones; organic catalysis; proline

\section{Introduction}

Enantioselective organocatalysis via enamines has received much attention in recent years. ${ }^{[1]}$ Since the first reports on the asymmetric direct aldol reaction catalyzed by proline, ${ }^{[2]}$ many organocatalysts have been synthesized with the aim of increasing the reactivity and stereoselectivity. Indeed, proline may be used in up to $30 \mathrm{~mol} \%$. Moreover, in several cases, for instance, in the aldol reaction between ketones and aryl aldehydes, the enantio- and diastereoselectivities were not good. ${ }^{[3]}$ In order to achieve higher stereoselectivities more complex organocatalysts have been designed and reactions at low temperature (down to $-40^{\circ} \mathrm{C}$ ) have been carried out. ${ }^{[4]}$ However, the increased complexity is not a synonym of higher stereoselectivity, for instance a Cinchona-derived proline gave low enantioselectivity in the reaction between cyclohexanone and 4-nitrobenzaldehyde. ${ }^{[4]}$ Usually, these organocatalysts are substituted prolinamides of the general structure I (Figure 1) in which the introduction of additional hydrogen bonding sites can improve their performances.
Several examples are shown in Figure 2. Usually, these reactions have been carried out in organic solvents. The proline-catalyzed direct aldol reaction in water does not work. ${ }^{[5]}$ Recently, the organocatalyzed direct aldol reaction in water has been indipendently reported by Hayashi ${ }^{[6]}$ and Barbas III. ${ }^{[5]}$ Previously, the aqueous aldol reaction between acetone and 4-nitrobenzaldehyde catalyzed by a nicotine metabolite was reported ${ }^{[7]}$ Barbas III used the TFA salt of a pyrrolidine derivative bearing long alkyl groups as catalyst in the reaction between cyclic ketones and aryl aldehydes while Hayashi used a TBDPS-protected hydroxyproline. Interesting results, for the same reactions, were previously reported using proline/D-CSA in water ${ }^{[8]}$ Since 2006, several papers appeared on this topic. Simple tryptophan, ${ }^{[9]}$ or other aromatic

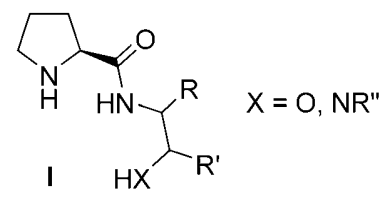

Figure 1. Substituted prolinamdies. 


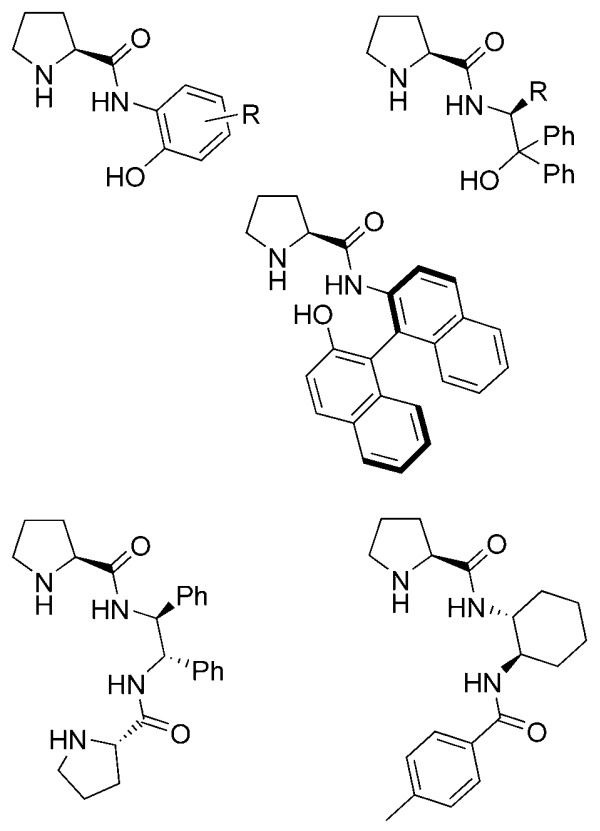

Figure 2. Examples of substituted prolinamides as organocatalysts for the asymmetric direct aldol reaction.

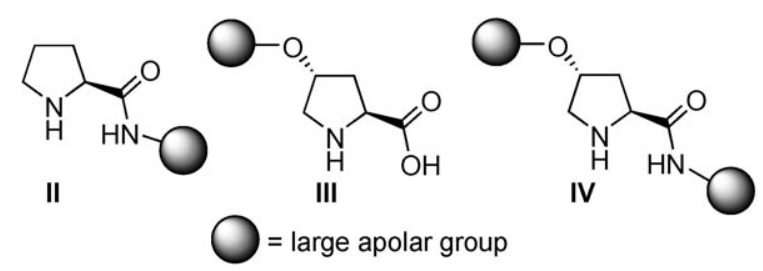

Figure 3. General structure of substituted proline derivatives as catalysts for aldol reaction in water.

amino acids, ${ }^{[10]}$ and dipeptides, in aqueous media ${ }^{[11]}$ or in the presence of water and additives ${ }^{[12]}$ were used. Apart from these molecules, the asymmetric direct aldol reaction in water has been carried out with mol- ecules of general formulae II, III and IV (Figure 3). In several cases, additives were also employed. ${ }^{[13]}$

In Figure 4 are reported several examples of organocatalysts of type II-IV for the asymmetric direct aldol reaction in water. Also several prolinamides, which were previously used in organic solvents (see Figure 2), were subsequently successfully employed in water ${ }^{[13 c, e, g, 1]}$ In addition to these proline-derived organocatalysts, also simple primary amino acid-derived organocatalysts $^{[14 a]}$ or more expensive amino acid-derived and diamine-substituted organocatalysts ${ }^{[14 b, c]}$ were employed in water. Depending on the nature of the organocatalyst, different amounts of catalyst can be used, from $20 \mathrm{~mol} \%$ in the presence of $20 \mathrm{~mol} \%$ of an additive to $0.5 \mathrm{~mol} \%$ at $-10^{\circ} \mathrm{C}$. Stereoselectivities ranged from good to high, depending on the complexity of the catalyst. Considering the complexity of the molecule and the observed stereoselectivities, in our opinion the best results have been obtained using the Hayashi's catalyst (10 or $1 \mathrm{~mol} \%)^{[13 \mathrm{k}]}$

Since the substrates are insoluble in water, a topic of debate has been opened as to whether some of these reactions really are "all wet". ${ }^{[15]}$ Hayashi has proposed that these reactions might be better considered as carried out "in the presence of water". ${ }^{[16]}$ On the other hand, Blackmond has raised doubts about the greenness of organocatalytic reactions carried out in the presence of water. ${ }^{[17]}$

We believe that the development of small organic molecules capable of catalyzing enantioselective reactions using water as reaction medium is still attracting great interest. In this context, we started a research project in order to find new organocatalysts, structurally simple, which are able to catalyze the asymmetric aldol reaction in water in low amounts $(<10 \mathrm{~mol} \%)$ without the need of additives. In the last years our efforts have been devoted to the investigation of new recyclable proline-derived organocatalysts ${ }^{[18]}$ and to the elucidation of some mechanistic aspects of pro-<smiles>[R16]c1ccc2ccccc2c1-c1c(NC(=O)C2CCCN2)ccc2ccccc12</smiles><smiles>CCCCOC1CNC(C(=O)O)C1</smiles>

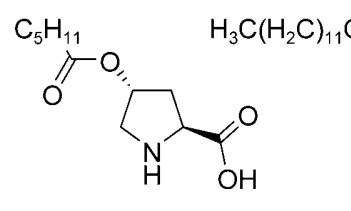<smiles>O=C(O)C1CCCN1</smiles>

TBSO,<smiles>CCOC(=O)C(O)C(NC(=O)C1CC(C)CN1)C(=O)OCC</smiles>

Figure 4. Examples of organocatalysts of types II-IV for the asymmetric direct aldol reaction in water. 


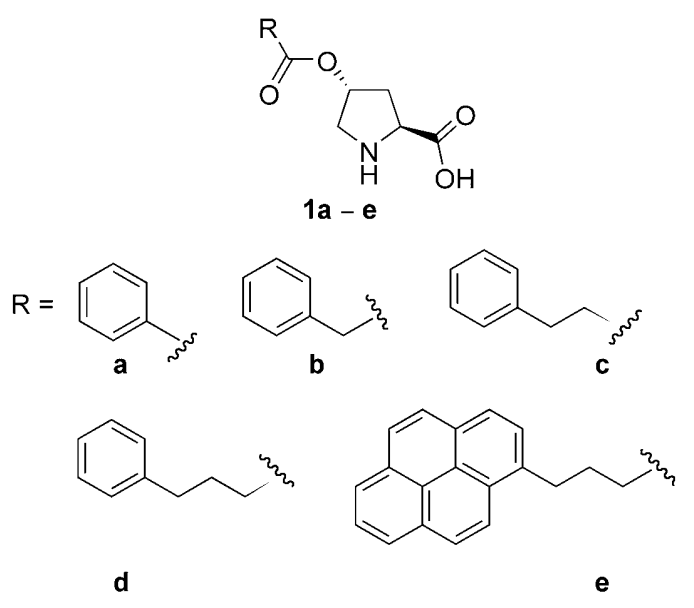

Figure 5. Structure of catalysts 1a-e.

line-catalyzed reactions. ${ }^{[19]}$ From a green chemistry point of view such studies are interesting because the direct aldol reaction is atomically economic, a low amount of an organocatalyst can be employed and the reaction medium is water.

\section{Results and Discussion}

With the aim to discover new simple organocatalysts for the direct asymmetric aldol reaction in water, we prepared five new proline derivatives 1a-e. The $\mathrm{R}$ group was varied in such a way to obtain molecules with increased hydrophobicity going from a phenyl to a propylpyrene substituent (Figure 5).

Compounds 1a-e were easily prepared from $\mathrm{N}$ Cbz-4-hydroxyproline 2 by benzylation and subsequent esterification in the presence of DCC/DMAP followed by removal of the protecting groups by catalytic hydrogenolysis (Scheme 1). Products were obtained in $83-97 \%$ overall yield.

As a first step, we screened several solvents for the reaction between cyclohexanone and 4-nitro-benzaldehyde (Table 1). As catalyst we used the most hydro-

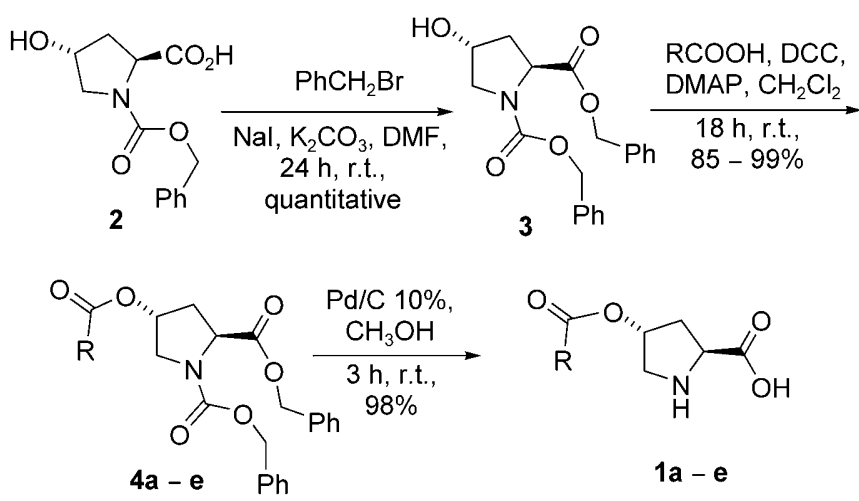

Scheme 1. Synthesis of catalysts 1a-e.
Table 1. Effect of the solvent on the catalytic aldol reaction between cyclohexanone and 4-nitro-benzaldehydes catalyzed by $1 e^{[a]}$

\begin{tabular}{lllll} 
& & & \\
\hline Entry & Solvent & Conv. $^{[\mathrm{b}]}[\%]$ & anti/syn $^{[\mathrm{c}]}$ & $e e^{[\mathrm{d}]}[\%]$ \\
\hline 1 & Toluene & 47 & $69 / 31$ & 96 \\
2 & $\mathrm{CHCl}_{3}$ & 60 & $69 / 31$ & 94 \\
3 & $\mathrm{DMSO}_{2}$ & 99 & $75 / 25$ & 93 \\
4 & $\mathrm{H}_{2} \mathrm{O}$ & 99 & $95 / 5$ & 98 \\
5 & $\mathrm{H}_{2} \mathrm{O}^{[\mathrm{f}]}$ & 99 & $92 / 8$ & 96 \\
6 & none $_{\text {solvent, } 6 \mathrm{~h}, \text { r.t. }}$ & $48^{[\mathrm{e}]}$ & $59 / 41$ & 87 \\
\hline
\end{tabular}

[a] Reaction conditions: cyclohexanone $(260 \mu \mathrm{L}, 2.5 \mathrm{mmol})$, aldehyde $(75.5 \mathrm{mg}, 0.5 \mathrm{mmol})$ catalyst $(0.05 \mathrm{mmol})$, solvent $(175 \mu \mathrm{L})$.

[b] Yields: $\geq 95 \%$ of conversion.

[c] Determined by ${ }^{1} \mathrm{H}$ NMR of the crude product.

[d] Determined by HPLC using a chiral stationary phase.

[e] Yield 38\%.

[f] Common tap-water.

phobic one (1e, $10 \mathrm{~mol} \%$ ). Both diastereoselectivity and conversion were not good when toluene and chloroform were used. DMSO showed increased conversion and diastereoselectivity, while water gave the highest stereoselectivity. Even undistilled water showed a similar behaviour (entry 5). Each solvent gave a high $e e$ value. When the reaction was carried out under neat conditions (entry 6) low yield and very low diastereoselectivity were observed coupled with a decreased enantioselectivity.

Then, using water as reaction medium, we investigated the above reaction employing different amounts of catalyst 1e (Table 2). Using a larger amount $(10 \mathrm{~mol} \%)$ of catalyst the reaction was faster but stereoselectivity was lower than in the other cases. The amount was decreased up to $0.5 \mathrm{~mol} \%$. After $24 \mathrm{~h}$ the conversion was not good but $d r$ and ee values were high. Noticeably, using $2 \mathrm{~mol} \%$ of catalyst after $24 \mathrm{~h}$, we obtained an almost quantitative conversion and excellent stereoselectivity. Even with $1 \mathrm{~mol} \%$ of catalyst results were very good.

Using catalyst 1e $(2 \mathrm{~mol} \%)$ we investigated the effect of different amount of water (Table 3). When a stoichiometric amount of water was used (entry 1 ) the conversion was not good. However, using 5 or more equivalents of water (entries 2-4) a complete conversion was observed. In each case stereoselectivities were high but, when a large amount of water ( $c a$. 20 equiv.) was employed, we obtained excellent diastereo- and enantioselectivity.

We also investigated if a lower amount of cyclohexanone can be employed. In Table 4 results of the reaction performed with $1.5,3$ and 5 equivalents of 
Table 2. Effect of the amount of the catalyst in the aldol reaction between cyclohexanone and 4-nitrobenzaldehyde catalyzed by 1e. ${ }^{[a]}$

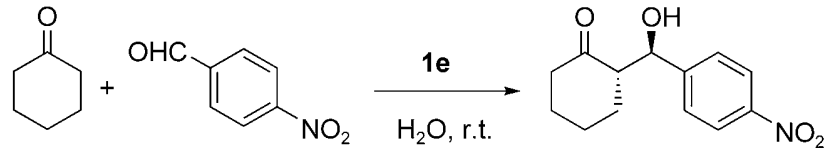

\begin{tabular}{llllll}
\hline Entry & Cat. $(\mathrm{mol} \%)$ & $t[\mathrm{~h}]$ & Conv. $^{[\mathrm{b}]}[\%]$ & anti/syn $^{[\mathrm{c}]}$ & $e e^{[\mathrm{d}]}[\%]$ \\
\hline 1 & 10 & 6 & 99 & $95 / 5$ & 98 \\
2 & 5 & 6.5 & $>99$ & $97 / 3$ & 99 \\
3 & 2 & 24 & $>99$ & $99 / 1$ & $>99$ \\
4 & 1 & 24 & 96 & $97 / 3$ & $>99$ \\
5 & 0.5 & 24 & 49 & $96.5 / 3.5$ & 99 \\
\hline
\end{tabular}

[a] Reaction conditions: cyclohexanone $(260 \mu \mathrm{L}, 2.5 \mathrm{mmol})$, aldehyde (75.5 mg, $0.5 \mathrm{mmol})$, water $(175 \mu \mathrm{L})$, room temperature.

[b] Yields: $\geq 95 \%$ of conversion.

[c] Determined by ${ }^{1} \mathrm{H}$ NMR of the crude product.

[d] Determined by HPLC using a chiral stationary phase.

Table 3. Effect of the amount of water in the aldol reaction between cyclohexanone and 4-nitrobenzaldehyde catalyzed by 1 e. $^{[a]}$

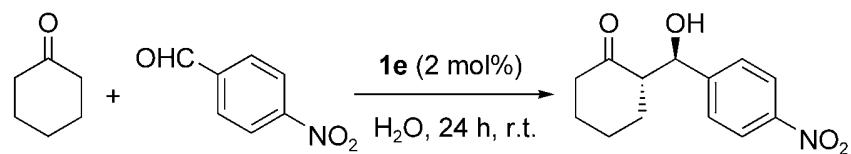

\begin{tabular}{lllll}
\hline Entry & $\mathrm{H}_{2} \mathrm{O}[\mu \mathrm{L}]$ & Conv. $^{[\mathrm{b}]}[\%]$ & ${\text { anti } / \text { syn }^{[\mathrm{c}]}}$ & $e e^{[\mathrm{d}]}[\%]$ \\
\hline 1 & 9 & 30 & $90 / 10$ & 96 \\
2 & 45 & $>99$ & $93 / 7$ & 97 \\
3 & 90 & $>99$ & $97 / 3$ & 99 \\
4 & 175 & $>99$ & $99 / 1$ & $>99$ \\
\hline
\end{tabular}

[a] Reaction conditions: cyclohexanone $(260 \mu \mathrm{L}, 2.5 \mathrm{mmol})$, aldehyde $(75.5 \mathrm{mg}, 0.5 \mathrm{mmol})$, water (see Table), room temperature.

[b] Yields: $\geq 95 \%$ of conversion.

[c] Determined by ${ }^{1} \mathrm{H}$ NMR of the crude product.

[d] Determined by HPLC using a chiral stationary phase.

ketone are reported. The data obtained show that the aldol product can be obtained in high yield and stereoselectivity even with only 1.5 equivalents of ketone.

Finally, we investigated the effect of the reaction temperature using water as reaction medium and catalyst 1e $(2 \mathrm{~mol} \%)$ (Table 5). No differences were observed in the range $25-40^{\circ} \mathrm{C}$ while at higher temperature $\left(50^{\circ} \mathrm{C}\right)$ a small decrease in diastereoselectivity coupled with a decrease in conversion was observed. Noticeably, the enantioselectivity was excellent in each case.

After these preliminary observations we tested catalysts 1a-e using water as reaction medium, 5 equiv. of cyclohexanone, $c a$. 20 equiv. of water, $2 \mathrm{~mol} \%$ of
Table 4. Effect of the amount of cyclohexanone in the aldol reaction between cyclohexanone and 4-nitrobenzaldehyde catalyzed by 1 . $^{[a]}$

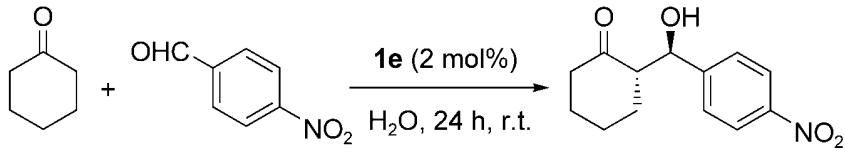

\begin{tabular}{|c|c|c|c|c|}
\hline Entry & $\begin{array}{l}\text { Cyclohexanone } \\
\text { [equiv.] }\end{array}$ & $\begin{array}{l}\text { Conv. }^{[\mathrm{b}]} \\
{[\%]}\end{array}$ & $\begin{array}{l}\text { anti/ } \\
\operatorname{syn}^{[\mathrm{c}]}\end{array}$ & $\begin{array}{l}e e^{[\mathrm{d}]} \\
{[\%]}\end{array}$ \\
\hline 1 & 1.5 & 97 & $95 / 5$ & 99 \\
\hline 2 & 3 & $>99$ & $95 / 5$ & 99 \\
\hline 3 & 5 & $>99$ & $99 / 1$ & $>99$ \\
\hline
\end{tabular}

[a] Reaction conditions: cyclohexanone (see Table), aldehyde $(75.5 \mathrm{mg}, 0.5 \mathrm{mmol})$, water $(175 \mu \mathrm{L})$, room temperature.

[b] Yields: $\geq 95 \%$ of conversion.

[c] Determined by ${ }^{1} \mathrm{H}$ NMR of the crude product.

[d] Determined by HPLC using a chiral stationary phase.

Table 5. Effect of the temperature on the catalytic aldol reaction between cyclohexanone and 4-nitrobenzaldehydes catalyzed by $1 \mathbf{1 e}^{[\mathrm{a}]}$

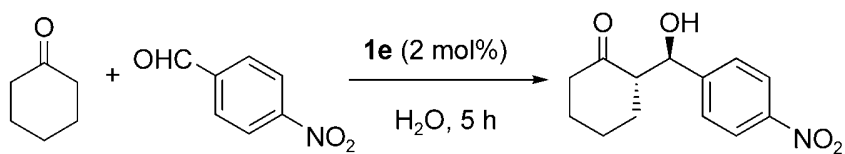

\begin{tabular}{lllll}
\hline Entry & $T\left[{ }^{\circ} \mathrm{C}\right]$ & Conv. $^{[\mathrm{b}]}[\%]$ & ${\text { anti } / \text { syn }^{[\mathrm{c}]}}$ & $e e^{[\mathrm{d}]}[\%]$ \\
\hline $1^{[\mathrm{e}]}$ & 25 & 90 & $97 / 3$ & $>99$ \\
2 & 35 & 92 & $96.5 / 3.5$ & $>99$ \\
3 & 40 & 90 & $96 / 4$ & $>99$ \\
4 & 50 & 60 & $93 / 7$ & $>99$
\end{tabular}

[a] Reaction conditions: cyclohexanone $(260 \mu \mathrm{L}, 2.5 \mathrm{mmol})$, aldehyde $(75.5 \mathrm{mg}, 0.5 \mathrm{mmol})$ catalyst $(0.01 \mathrm{mmol})$, solvent $(175 \mu \mathrm{L})$.

[b] Yields: $\geq 95 \%$ of conversion.

[c] Determined by ${ }^{1} \mathrm{H}$ NMR of the crude product.

[d] Determined by HPLC using a chiral stationary phase. ${ }^{[\mathrm{e}]}$ When the reaction is carried out for $24 \mathrm{~h}$, conversion is complete.

catalyst loading at room temperature. We used these conditions in the reaction between cyclohexanone and two aldehydes (benzaldehyde and 4-nitrobenzaldehyde, Table 6).

Going from the less hydrophobic to the most hydrophobic catalyst, we observed an increased enantioselectivity in the reaction between cyclohexanone and benzaldehyde while the diastereoselectivity was similar except when 1a was employed. In this case a lower diastereoselectivity was observed. When the reaction between cyclohexanone and 4-nitrobenzaldehyde was investigated, catalysts 1a-e showed a more marked difference. Indeed, both diastereoselectivity and enan- 
Table 6. Catalytic aldol reactions between cyclohexanone and benzaldehyde or 4-nitrobenzaldehyde catalyzed by 1a-e. ${ }^{[a]}$

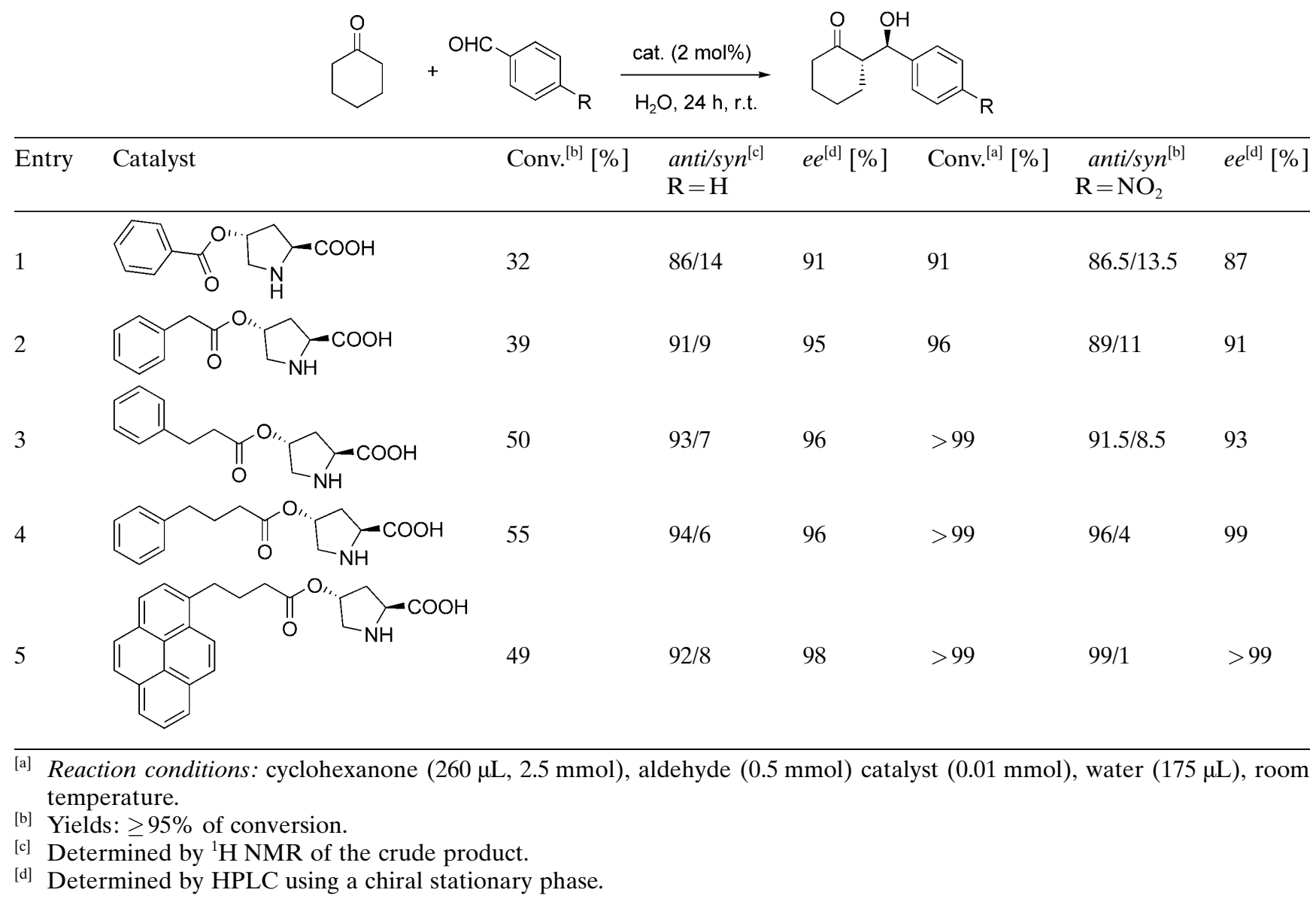

tioselectivity increased when the hydrophobicity of the catalyst was increased. Finally, higher conversions were observed with the more hydrophobic catalysts. It is interesting to note that with 4-acyloxyproline catalysts, in which the acyl group was a linear alkyl chain, the diastereoselectivity and enantioselectivity decreased on going from the less hydrophobic to the most hydrophobic catalyst. ${ }^{[13 \mathrm{k}]}$

As can be seen from the results summarized in Table 6, catalysts 1d and e can efficiently catalyze the direct asymmetric aldol reaction with a high level of stereoselectivity. Then, we carried out several aldol reactions using the above catalysts in order to demonstrate their catalytic activity. First we checked the aldol reaction between cyclohexanone and several aryl aldehydes using 1d as catalyst.

Results are summarized in Table 7. Yields and both diastereo- and enantioselectivities (94->99\%) were high. Lower yields were observed only with the less reactive substrates.

When cyclopentanone was employed interesting results were obtained (Table 8). In particular, enantioselectivities were excellent (97->99\%).

We further investigated compound 1e as catalyst in the reaction between aryl aldehydes and cyclohexa-
Table 7. Catalytic aldol reactions between cyclohexanone and aryl aldehydes catalyzed by $\mathbf{1 d}{ }^{[\mathrm{a}]}$

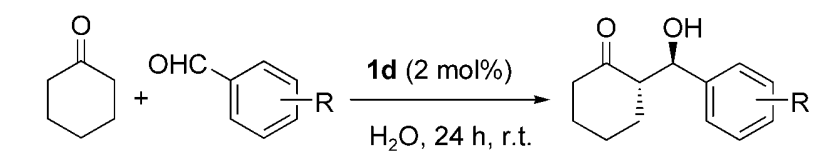

\begin{tabular}{lllll}
\hline Entry & $\mathrm{R}$ & Conv. $^{[\mathrm{b}]}[\%]$ & anti/syn $^{[\mathrm{c}]}$ & $e e^{[\mathrm{d}]}[\%]$ \\
\hline 1 & $\mathrm{H}$ & 55 & $94 / 6$ & 96 \\
2 & $4-\mathrm{NO}_{2}$ & $>99$ & $96 / 4$ & 99 \\
3 & $2-\mathrm{naphthyl}$ & 45 & $92 / 8$ & 99 \\
4 & $4-\mathrm{CN}$ & $>99$ & $96 / 4$ & 98 \\
5 & $2-\mathrm{Cl}$ & $>99$ & $97 / 3$ & 98 \\
$6^{[\mathrm{e}]}$ & $3-\mathrm{OCH}_{3}$ & 82 & $90 / 10$ & 94 \\
7 & $4-\mathrm{CF}_{3}$ & 98 & $96 / 4$ & 99 \\
8 & $2-\mathrm{NO}_{2}$ & 97 & $99 / 1$ & $>99$ \\
\hline
\end{tabular}

[a] Reaction conditions: cyclohexanone $(260 \mu \mathrm{L}, 2.5 \mathrm{mmol})$, aldehyde $\quad(0.5 \mathrm{mmol})$ catalyst $\quad(0.01 \mathrm{mmol})$, water $(175 \mu \mathrm{L})$, room temperature.

[b] Yields: $\geq 95 \%$ of conversion.

[c] Determined by ${ }^{1} \mathrm{H}$ NMR of the crude product.

[d] Determined by HPLC using a chiral stationary phase.

[e] Reaction time: $72 \mathrm{~h}$. 
Table 8. Catalytic aldol reactions between cyclopentanone and aryl aldehydes catalyzed by $\mathbf{1 d}{ }^{[\mathrm{a}]}$

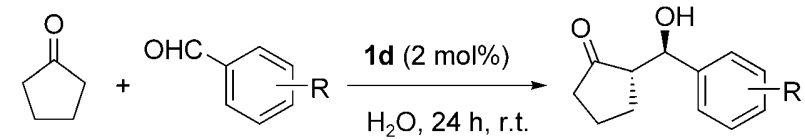

\begin{tabular}{lllll}
\hline Entry & $\mathrm{R}$ & Conv. $^{[\mathrm{b}]}[\%]$ & ${\text { anti } / \text { syn }^{[\mathrm{c}]}} e e^{[\mathrm{d}]}[\%]$ \\
\hline 1 & $\mathrm{H}$ & 83 & $89 / 11$ & 97 \\
2 & $4-\mathrm{NO}_{2}$ & $>99$ & $87 / 13$ & 98 \\
3 & 2-naphthyl & 84 & $89 / 11$ & 97 \\
4 & $4-\mathrm{CN}$ & $>99$ & $85 / 15$ & $>99$ \\
5 & $2-\mathrm{Cl}$ & $>99$ & $90 / 10$ & 98 \\
$6^{[\mathrm{e}]}$ & $3-\mathrm{OCH}_{3}$ & 95 & $85 / 15$ & 97 \\
7 & $4-\mathrm{CF}_{3}$ & $>99$ & $87 / 13$ & 97 \\
8 & $2-\mathrm{NO}_{2}$ & $>99$ & $92 / 8$ & 99 \\
\hline
\end{tabular}

[a] Reaction conditions: cyclopentanone $(220 \mu \mathrm{L}, 2.5 \mathrm{mmol})$, aldehyde $(0.5 \mathrm{mmol})$ catalyst $(0.01 \mathrm{mmol})$, water $(175 \mu \mathrm{L})$, room temperature.

[b] Yields: $>95 \%$ of conversion.

[c] Determined by ${ }^{1} \mathrm{H}$ NMR of the crude product.

[d] Determined by HPLC using a chiral stationary phase.

[e] Reaction time: $72 \mathrm{~h}$.

Table 9. Catalytic aldol reactions between cyclohexanone and aryl aldehydes catalyzed by $\mathbf{1 e} .^{[a]}$

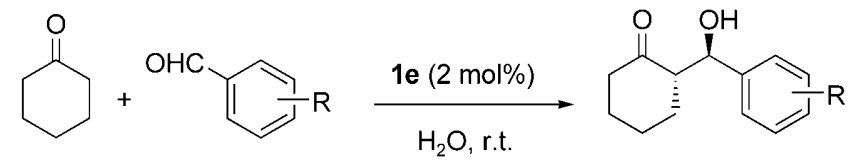

\begin{tabular}{llllll}
\hline Entry & $\mathrm{X}$ & $t[\mathrm{~h}]$ & Conv. $^{[\mathrm{b}]}[\%]$ & anti/syn $^{[\mathrm{c}]}$ & $e e^{[\mathrm{d}]}[\%]$ \\
\hline 1 & $4-\mathrm{NO}_{2}$ & 24 & $>99$ & $99 / 1$ & $>99$ \\
2 & 4-Cl & 24 & 79 & $94 / 6$ & 99 \\
3 & $4-\mathrm{CN}$ & 24 & 98 & $96 / 4$ & 97 \\
4 & 2-naphthyl & 48 & 52 & $91.5 / 8.5$ & 99 \\
5 & $\mathrm{H}$ & 48 & 66 & $91 / 9$ & 98 \\
6 & 3-OCH & 72 & 78 & $91 / 9$ & 91 \\
7 & $4-\mathrm{CH}_{3}$ & 72 & 42 & $87 / 13$ & 87 \\
8 & $4-\mathrm{CF}_{3}$ & 24 & 95 & $96 / 4$ & $>99$ \\
9 & $4-\mathrm{Br}$ & 24 & 80 & $93 / 7$ & $>99$ \\
10 & $2-\mathrm{Cl}$ & 24 & 91 & $97 / 3$ & 97 \\
11 & 2-F & 24 & 97 & $97 / 3$ & 96 \\
\hline
\end{tabular}

[a] Reaction conditions: cyclohexanone $(260 \mu \mathrm{L}, 2.5 \mathrm{mmol})$, aldehyde $(0.5 \mathrm{mmol})$ catalyst $(0.01 \mathrm{mmol})$, water $(175 \mu \mathrm{L})$, room temperature.

[b] Yields: $\geq 95 \%$ of conversion.

[c] Determined by ${ }^{1} \mathrm{H}$ NMR of the crude product.

[d] Determined by HPLC using a chiral stationary phase.

none (Table 9) and cyclopentanone (Table 10). Stereoselectivities were high. In particular, in the case of cyclohexanone, enantioselectivities ranged from 96 to $>99 \%$. Only in the cases of 3-methoxy and 4-methyl derivatives (Table 9, entries 6 and 7) was the enantioselectivity slightly lower (91 and $87 \%$, respectively).
Table 10. Catalytic aldol reactions between cyclopentanone and aryl aldehydes catalyzed by $\mathbf{1 e} .^{[\mathrm{a}]}$

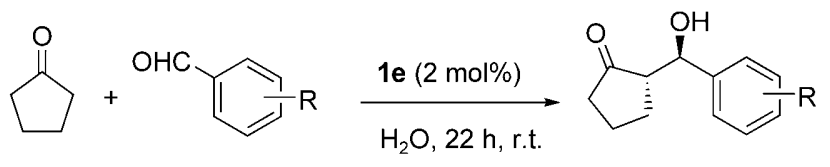

\begin{tabular}{lllll}
\hline Entry & $\mathrm{R}$ & Conv. $^{[\mathrm{b}]}[\%]$ & ${\text { anti } / \text { syn }^{[\mathrm{c}]}}$ & $e e^{[\mathrm{d}]}[\%]$ \\
\hline 1 & $4-\mathrm{NO}_{2}$ & $>99$ & $88 / 12$ & $>99$ \\
2 & $2-\mathrm{NO}_{2}$ & $>99$ & $92 / 8$ & 99 \\
3 & 3-NO & $>99$ & $87 / 13$ & 99 \\
4 & $4-\mathrm{CF}_{3}$ & $>99$ & $85 / 15$ & 98 \\
5 & $4-\mathrm{CN}$ & $>99$ & $86 / 14$ & 99 \\
6 & $4-\mathrm{Cl}$ & $>99$ & $88 / 12$ & 98 \\
7 & $2-\mathrm{Cl}$ & $>99$ & $88 / 12$ & 98 \\
8 & $\mathrm{H}$ & 97 & $86 / 14$ & 96 \\
9 & 2-naphthyl & 90 & $88 / 12$ & 98 \\
10 & $4-\mathrm{Br}_{1}$ & 98 & $87 / 13$ & 98 \\
11 & 4-CH & 85 & $85 / 15$ & 96 \\
12 & $4-\mathrm{OCH}_{3}$ & 48 & $82 / 18$ & 97 \\
13 & 3- $\mathrm{OCH}_{3}$ & 97 & $80 / 20$ & 93
\end{tabular}

[a] Reaction conditions: cyclopentanone $(220 \mu \mathrm{L}, 2.5 \mathrm{mmol})$, aldehyde $(0.5 \mathrm{mmol})$ catalyst $(0.01 \mathrm{mmol})$, water $(175 \mu \mathrm{L})$, room temperature.

[b] Yields: $\geq 95 \%$ of conversion.

[c] Determined by ${ }^{1} \mathrm{H}$ NMR of the crude product.

[d] Determined by HPLC using a chiral stationary phase.

Again, excellent results were obtained when catalyst 1e was used in the reaction with cyclopentanone (Table 10). Enantioselectivities ranged from 96 to $>99 \%$, only the 3-methoxy derivative showed a sligthly lower enantioselectivity (93\%).

Finally, we checked the aldol reaction between other ketones (acetone, 2-butanone, tetrahydro- $4 \mathrm{H}$ pyran-4-one, 4-methylcyclohexanone, cycloheptanone) and 4-nitrobenzaldehyde using catalyst $1 e(2 \mathrm{~mol} \%)$ (Table 11). The reaction with acetone was carried out both in the presence and in the absence of water. In the first case we obtained the aldol product in high yield $(84 \%)$ and low enantioselectivity (11\%) (entry 1). When we carried out the reaction without water (entry 2) we obtained the aldol product in low yield $(18 \%)$ and good enantioselectivity (76\%). However, it is worth noting that the configuration of aldol product was reversed. In our opinion the presence of water increased the activity of the catalyst because the more hydrophilic medium increased the affinity of the hydrophobic aldehyde to the hydrophobic catalyst. When water was absent, the aldehyde was well dissolved in acetone and this caused a lower yield. More difficult to explain is the observed enantioselectivity in the presence of water. By contrast, the reaction between cyclohexanone and 4-nitrobenzaldehyde under neat conditions did not show a reversed enantioselectivity. This is probably due to the different hydrophilicity between the two ketones. 
Table 11. Catalytic aldol reactions between several ketones and 4-nitrobenzaldehyde catalyzed by $\mathbf{1 e} .^{[a]}$<smiles>[R]CC([R])=O</smiles>

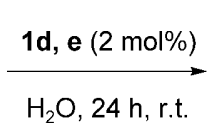<smiles>[R]C(=O)C([R])[C@H](O)c1ccc([N+](=O)[O-])cc1</smiles>

\begin{tabular}{|c|c|c|c|c|c|}
\hline Entry & Reaction conditions & Product & Conv $^{[\mathrm{b}]}[\%]$ & $a n t i / s y n^{[\mathrm{c}]}$ & $e e^{[\mathrm{d}]}[\%]$ \\
\hline 1 & $\mathbf{A}^{[\mathrm{e}]}$ & & 84 & - & 11 \\
\hline 2 & $\mathbf{B}^{[\mathrm{e}]}$ & & 18 & - & 76 \\
\hline 3 & $\mathbf{A}^{[\mathrm{e}]}, \mathbf{B}^{[\mathrm{e}]}$ & & $\mathrm{nr}$ & - & - \\
\hline 4 & $\mathbf{A}$ & & $\mathrm{nr}$ & - & - \\
\hline 5 & $\mathbf{A}$ & & 35 & $97.5 / 2.5$ & 95 \\
\hline 6 & $\mathbf{A}$ & & 97 & $94 / 6$ & 99 \\
\hline 7 & $\mathbf{C}$ & & 96 & $92 / 8$ & 98 \\
\hline
\end{tabular}

[a] Reaction conditions: A, ketone $(2.5 \mathrm{mmol})$, aldehyde $(0.5 \mathrm{mmol})$ catalyst $\mathbf{1 e}(0.01 \mathrm{mmol})$, water $(175 \mu \mathrm{L})$, room temperature; B, ketone $(2.5 \mathrm{mmol})$, aldehyde $(0.5 \mathrm{mmol})$ catalyst $\mathbf{1 e}(0.01 \mathrm{mmol})$, room temperature; $\mathbf{C}$, ketone $(2.5 \mathrm{mmol})$, aldehyde $(0.5 \mathrm{mmol})$ catalyst $\mathbf{1 d}(0.01 \mathrm{mmol})$, water $(175 \mu \mathrm{L})$, room temperature.

[b] Yields: $\geq 95 \%$ of conversion.

[c] Determined by ${ }^{1} \mathrm{H}$ NMR of the crude product.

[d] Determined by HPLC using a chiral stationary phase.

[e] For $48 \mathrm{~h}$.

Using the same conditions for acetone, 2-butanone gave very poor results (entry 3 ). This can be viewed as an interesting result because 1e appears to be a substrate-selective catalyst. The same behaviour was observed when cycloheptanone was used (entry 4). The reaction did not take place. However, it should be remembered that cycloheptanone is not a very reactive substrate. Indeed, only few papers report aldol reactions with cycloheptanone under aqueous condition. ${ }^{[5,13 \mathrm{~g}, 18 \mathrm{e}]}$

Tetrahydro- $4 H$-pyran-4-one gave high stereoselectivities but low conversion (entry 5), whereas excel- lent results were obtained using 4-methylcyclohexanone both with catalysts 1e and 1d (entries 6 and 7).

From a mechanistic point of view, water plays a crucial role. In fact, the data of the reactions carried out with cyclohexanone under aqueous and neat conditions (Table 1, entries 4, 5 and 6) showed that water enhances the catalyst activity (yield from 38 to $99 \%$ ), diastereoselectivity (from 59/41 to 95/5) and enantioselectivity (from 87 to $98 \%$ ). We hypothesize that, under the reaction conditions employed, a hydrophobic region and a hydrophilic region can be formed in the presence of catalyst 1e, as depicted in Figure 6. 


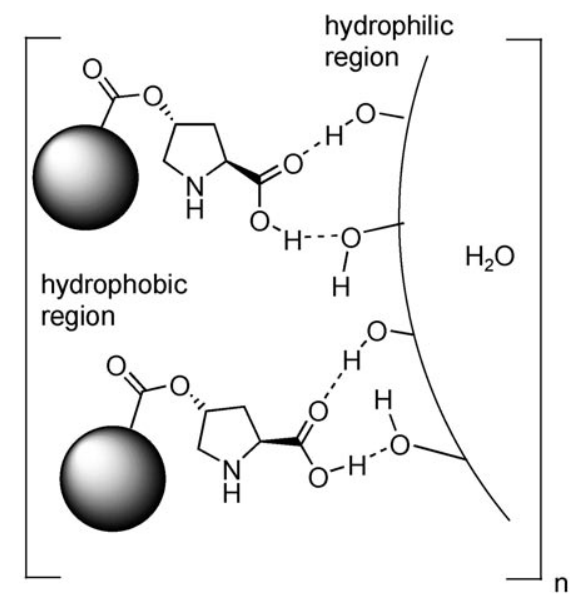

Figure 6. Proposed structure of catalyst 1e in the presence of water.

The enhanced activity of organic catalysis on water has been recently theoretically investigated. Free $\mathrm{OH}$ groups of interfacial water molecules play a key role in catalyzing reactions via the formation of hydrogen bonds. ${ }^{[20]}$

Quantum mechanical calculations have predicted the transition state geometries for the reaction of cyclohexanone enamine with benzaldehyde. ${ }^{[21]}$ The transition states involving the $r e$ attack on the anti-enamine are lower in energy than the transition states for $s i$ attack on the syn-enamine. ${ }^{[21]}$ Following this mechanism, in order to explain the observed enhanced stereoselectivities, we hypothesize that transition state $\mathbf{A}$ (Figure 7) is highly stabilized because the hydrophobic aldehyde attacking the anti-enamine lies in the hydrophobic region. The excellent enantioselectivities observed can be explained by transition state B. In this case the less favoured attack of aldehyde on the syn-enamine is more destabilized because the hydrophobic aldehyde lies in the hydrophilic region. Finally, the high diastereoselectivities observed can be explained by transition state $\mathbf{C}$. In this case the attack of aldehyde on anti-enamine is more destabilized because the hydrophobic part of the aldehyde is directed towards the hydrophilic region. This model can explain the lower stereoselectivity observed when water is absent.

\section{Conclusions}

We have synthesized five new organocatalysts for the direct asymmetric aldol reaction. These catalysts are easily prepared in a few high-yielding steps, so they are easily accessible. Screening of these molecules show that the most hydrophobic compounds $\mathbf{1 d}$ and $\mathbf{e}$ are very active catalysts. Catalyst 1e can be used
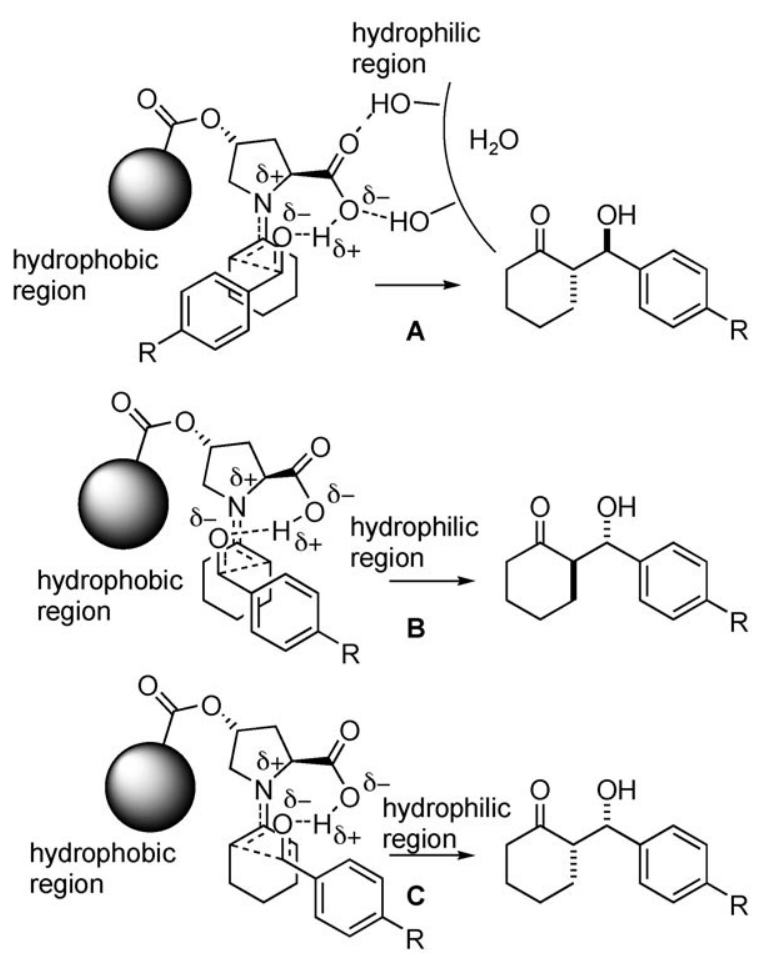

Figure 7. Proposed transition state model for the major stereoisomer $(\mathbf{A})$, its enantiomer $(\mathbf{B})$, and the minor diastereoisomer $(\mathbf{C})$.

down to $0.5 \mathrm{~mol} \%$ with excellent stereoselectivity and moderate yield after only $24 \mathrm{~h}$. This can be considered an interesting result since in several cases catalysts that are used in higher amounts (up to $20 \mathrm{~mol} \%$ ) required long reaction times. ${ }^{[4 c, f, i, k, 10,11,12,13 e, g]}$ In our case, the reaction conditions are very mild, water is used as reaction medium, there is no need to perform the reactions at low temperature to reach high stereoselectivity, indeed, reactions are carried out at room temperature and even higher temperatures can furnish aldol products in excellent stereoselectivity, no additives are used and, finally, only $2 \mathrm{~mol} \%$ of catalyst is employed. Aldol products are obtained from good to almost quantitative yields in a reasonable time and stereoselectivities are excellent in almost all the cases. In particular, aldol products from cyclopentanone are obtained in excellent enantioselectivities. This work demonstrates that derivatization of the proline moiety with the proper simple hydrophobic substituent in the 4-position can furnish highly active and stereoselective catalysts without the need of additional expensive chiral backbones in the molecule. In addition to Hayashi's catalyst, ${ }^{[13 k]}$ compounds $1 \mathbf{1 d}$ and e represent the best compromise between activity and simplicity of structure. When acetone was employed as donor compound great differences were observed both in yield and enantioselectivity when the reaction was carried 
out in the presence or in the absence of water. This is probably due to the higher hydrophilicity of the acetone compared to cyclic ketones. Finally, an explanation of the observed stereoselectivities for cyclic ketones in the presence of water was given.

\section{Experimental Section}

The NMR spectra were recorded on a Bruker $300 \mathrm{MHz}$ spectrometer using $\mathrm{CDCl}_{3}$ or DMSO- $d_{6}$ as solvent. Solidstate ${ }^{13} \mathrm{C}\{\mathrm{H}\}$ CP-MAS NMR spectra was recorded on a Bruker AV 400, $400 \mathrm{MHz}$ spectrometer with samples packed in zirconia rotors spinning at $13 \mathrm{kHz}$. FT-IR spectra were registered with a Shimadzu FTIR 8300 infrared spectrophotometer. Carbon and nitrogen contents were determined by combustion analysis in a Fisons EA 1108 elemental analyzer. Optical rotations were measured in chloroform on a Jasco P1010 polarimeter. Hydrogenation reactions were carried out using a Parr apparatus. Flash chromatography was carried out using Macherey-Nagel $(0.04-0.063 \mathrm{~mm})$ silica gel. Melting points were determined using a Köfler hot plate and are not corrected. Chiral HPLC analyses were performed using a Shimadzu LC-10AD apparatus equipped with an SPD-M10 A UV detector and Daicel columns (OD$\mathrm{H}, \mathrm{AD}-\mathrm{H}, \mathrm{AS}-\mathrm{H})$ using hexane/2-propanol as eluent. Aldol products, except $(S)$-2-\{(R)-hydroxy[3-methoxyphenyl]methyl cyclopentanone, are known compounds and showed spectroscopic and analytical data in agreement with their structures (see Table 12 and Table 13). The configurations of products have been assigned by comparison with literature data. $N$-Cbz-4-hydroxy-proline $\mathbf{2}$ was commercially available (Aldrich). (2S,4R)-Dibenzyl 4-hydroxypyrrolidine-1,2-dicarboxylate 3 was prepared as reported in the literature. ${ }^{[2]}$

\section{General Procedure for the Synthesis of Compounds 4a-e}

To a solution of compound $3(562 \mathrm{mg}, 1.58 \mathrm{mmol})$ in anhydrous dichloromethane $(35 \mathrm{~mL})$ the proper carboxylic acid $(2.24 \mathrm{mmol})$ was added. The mixture was stirred for $10 \mathrm{~min}$ at $0^{\circ} \mathrm{C}$ under argon. Then, 1,3-dicyclohexylcarbodimide (DCC) $(2.24 \mathrm{mmol})$ and 4-(dimethylamino)-pyridine (DMAP) $(0.224 \mathrm{mmol})$ in dichloromethane $(10 \mathrm{~mL})$ were added and the mixture was stirred at $0^{\circ} \mathrm{C}$ for $15 \mathrm{~min}$. The reaction mixture was stirred overnight at room temperature under argon. After this period the dichloromethane solution was washed with water $(2 \times 30 \mathrm{~mL})$. The organic phase was dried with $\mathrm{MgSO}_{4}$ and concentrated under reduced pressure.

(2S,4R)-Dibenzyl 4-(benzoyloxy)pyrrolidine-1,2-dicarboxylate (4a): The residue was purified by column chromatography (petroleum ether/ethyl acetate, 6:1), to give compound 4a as a pale yellow solid; yield: $85 \%$; $[\alpha]_{D}^{26:}-39.7$ ( c 0.76 , $\left.\mathrm{CHCl}_{3}\right) ; \mathrm{mp} 75-77^{\circ} \mathrm{C} .{ }^{1} \mathrm{H}$ NMR $\left(\mathrm{CDCl}_{3}\right): \delta=2.14-2.23(\mathrm{~m}$, $1 \mathrm{H}), 2.36-2.46(\mathrm{~m}, 1 \mathrm{H}), 3.70-3.82(\mathrm{~m}, 2 \mathrm{H}), 4.51(\mathrm{ddd}, J=$ $7.9,7.9$ and $25.2 \mathrm{~Hz}, 1 \mathrm{H}), 4.92(\mathrm{~d}, J=14.4 \mathrm{~Hz}, 2 \mathrm{H}), 5.02-$ $5.13(\mathrm{~m}, 2 \mathrm{H}), 5.32-5.40(\mathrm{~m}, 1 \mathrm{H}), 7.41-707(\mathrm{~m}, 13 \mathrm{H}), 7.81$ (d, $J=7.5,2 \mathrm{H}) ;{ }^{13} \mathrm{C}$ NMR $\left(75 \mathrm{MHz}, \mathrm{CDCl}_{3}\right.$; two rotamers): $\delta=171.9,171.7,165.6,154.7,154.1,136.3136 .2,135.5,135.3$, $133.3,133.2,129.6,129.5,128.5,128.3,128.5,128.2,128,1$, $128.0,127.9,127.7,127.7,73.1,72.5,67.2,66.9,58.1,57.8$,
53.6, 52.6, 52.2, 36.6, 35.5; IR (nujol): $\tilde{v}_{\max }=1740,1700 \mathrm{~cm}^{-1}$; anal. calcd. for $\mathrm{C}_{27} \mathrm{H}_{25} \mathrm{NO}_{6}$ (459.49): C 70.58, H 5.48, N 3.05; found: C 70.67, H 5.45, N 3.09.

(2S,4R)-Dibenzyl 4-(2-phenylacetoxy)pyrrolidine-1,2-dicarboxylate (4b): The residue was purified by column chromatography (petroleum ether/ethyl acetate, 4:1), to give compound $\mathbf{4 b}$ as a yellow oil; yield: $92 \% ;[\alpha]_{\mathrm{D}}^{26}:-41.6(c$ $\left.0.89, \mathrm{CHCl}_{3}\right) .{ }^{1} \mathrm{H} \mathrm{NMR}\left(\mathrm{CDCl}_{3}\right): \delta=2.03-2.14(\mathrm{~m}, 1 \mathrm{H})$, 2.24-2.32 (m, 1H), $3.48(\mathrm{~d}, J=2.1 \mathrm{~Hz}, 2 \mathrm{H}), 3.53-3.70(\mathrm{~m}$, $2 \mathrm{H}), 4.39$ (ddd, $J=8.0,8.0$ and $29.8 \mathrm{~Hz}, 1 \mathrm{H}), 4.93(\mathrm{~d}, J=$ $19 \mathrm{~Hz}, 2 \mathrm{H}), 5.03-5.11(\mathrm{~m}, 2 \mathrm{H}), 5.13-5.20(\mathrm{~m}, 1 \mathrm{H}), 7.10-7.30$ $(\mathrm{m}, 15 \mathrm{H}) ;{ }^{13} \mathrm{CNMR}\left(75 \mathrm{MHz}, \mathrm{CDCl}_{3}\right.$; two rotamers): $\delta=$ $171.7,170.8,170.7,154.6,154.0,136.3,136.1,135.4,135.2$, $133.4,133.3,129.0,128.6,128.5,128,4,128.4,128.3,128.1$, 127.8, 127.2, 127.2, 72.9, 72.2, 67.3, 67.2, 67.0, 66.9, 57.9, 57.6, 52.4, 52.1, 41.1, 36.4, 35.4; IR (nujol): $\tilde{v}_{\max }=1740,1708 \mathrm{~cm}^{-1}$; anal. calcd. for $\mathrm{C}_{28} \mathrm{H}_{27} \mathrm{NO}_{6}$ (473.52): C 71.02, H 5.75, N 2.96; found: C 71.07, H 5.79, N 3.00.

(2S,4R)-Dibenzyl 4-(3-phenylpropanoyloxy)pyrrolidine1,2-dicarboxylate (4c): The residue was purified by column chromatography (petroleum ether/ethyl acetate, $3: 1$ ), to give compound $4 \mathbf{c}$ as a yellow oil; yield: $92 \% ;[\alpha]_{\mathrm{D}}^{26}:-41.6(c$ $\left.0.73, \mathrm{CHCl}_{3}\right) .{ }^{1} \mathrm{H} \mathrm{NMR}\left(\mathrm{CDCl}_{3}\right): \delta=2.22-2.31(\mathrm{~m}, 1 \mathrm{H})$, 2.35-2.45 (m, 1H), 2.68-2.73 (m, 2H), 2.98-3.04 (m, 2H), 3.66-3.87 (m, 2H), 4.50 (ddd, $J=8.1,8.1$ and $32.1 \mathrm{~Hz}, 1 \mathrm{H})$, $5.12(\mathrm{~d}, J=18.3 \mathrm{~Hz}, 2 \mathrm{H}), 5.22-5.35(\mathrm{~m}, 3 \mathrm{H}), 7.22-7.45(\mathrm{~m}$, $15 \mathrm{H}) ;{ }^{13} \mathrm{C} \mathrm{NMR}\left(75 \mathrm{MHz}, \mathrm{CDCl}_{3}\right.$; two rotamers): $\delta=172.6$, $172.6,172.4,172.1,155.1,154.5,140.4,140.4,136.7,136.6$, $135.9,135.6,129.0,128.9,128.8,128.7,128.6,128.6,128.5$, $128.3,126.8,126.7,72.9,72.2,67.7,67.5,67.3,58.4,58.0,52.9$, 52.5, 37.0, 36.1, 36.0, 31.3; IR (liquid film): $\tilde{v}_{\max }=1740$, $1712 \mathrm{~cm}^{-1}$ : anal. calcd. for $\mathrm{C}_{29} \mathrm{H}_{29} \mathrm{NO}_{6}$ (487.54): $\mathrm{C} 71.44, \mathrm{H}$ 6.00, N 2.87; found: C 71.47, H 6.04, N 2.90.

(2S,4R)-Dibenzyl 4-(4-phenylbutanoyloxy)pyrrolidine-1,2dicarboxylate (4d): The residue was purified by column chromatography (petroleum ether/ethyl acetate, 2:1), to give compound 4d as a pale orange oil; yield: $99 \%$; $[\alpha]_{\mathrm{D}}^{30}:-32.4$ (c $\left.0.63, \mathrm{CHCl}_{3}\right) .{ }^{1} \mathrm{H}$ NMR $\left(\mathrm{CDCl}_{3}\right): \delta=1.85-2.10(\mathrm{~m}, 3 \mathrm{H})$, 2.16-2.49 (m, 3H), 2.64-2.74 (m, 2H), 3.65-3.85 (m, 2H), 4.54 (ddd, $J=7.8,7.8$ and $21.9 \mathrm{~Hz}, 1 \mathrm{H}), 5.06(\mathrm{~d}, J=16.2 \mathrm{~Hz}$, $2 \mathrm{H}), 5.19-5.34(\mathrm{~m}, 3 \mathrm{H}), 7.16-7.44(\mathrm{~m}, 15 \mathrm{H}) ;{ }^{13} \mathrm{C}$ NMR $(75$ $\mathrm{MHz}, \mathrm{CDCl}_{3}$; two rotamers): $\delta=172.6,172.5,171.8,171.6$, $154.5,154.0,153.8,141.3,140.9,140.8,136.1,136.0,135.3$, $135.0,128.4,128.3,128.2,128.1,128.0,127.9,127.8,127.7$, $125.9,125.8,72.3,71.5,67.1,66.9,66.8,57.8,57.6,52.4,52.0$, 34.9, 34.8, 33.3, 26.1; IR (liquid film): $\tilde{v}_{\max }=1732,1705 \mathrm{~cm}^{-1}$; anal. calcd. for $\mathrm{C}_{30} \mathrm{H}_{31} \mathrm{NO}_{6}$ (501.57): C 71.84, H 6.23, N 2.79; found: C 71.79, H 6.20, N 2.85.

(2S,4R)-Dibenzyl 4-[4-(pyren-1-yl)butanoyloxy]pyrrolidine-1,2-dicarboxylate (4e): The residue was purified by column chromatography (petroleum ether/ethyl acetate, 7:1), to give compound $\mathbf{4 e}$ as a viscous pale yellow oil; yield: 93\%; $[\alpha]_{\mathrm{D}}^{24}:-411.7\left(\right.$ c $\left.0.72, \mathrm{CHCl}_{3}\right) .{ }^{1} \mathrm{H}$ NMR $\left(\mathrm{CDCl}_{3}\right): \delta=$ 2.06-2.13 (m, 3H), 2.25-2.34 (m, 3H), 3.21-3.30 (m, 2H), $3.52-3.69(\mathrm{~m}, 2 \mathrm{H}), 4.41$ (ddd, $J=8.1,8.1$ and $23.7 \mathrm{~Hz}, 1 \mathrm{H})$, $4.92(\mathrm{~d}, J=14 \mathrm{~Hz}, 2 \mathrm{H}), 5.04-5.20(\mathrm{~m}, 3 \mathrm{H}), 7.09-7.25(\mathrm{~m}$, $10 \mathrm{H}), 7.72(\mathrm{dd}, J=1.8$ and $7.5 \mathrm{~Hz}, 1 \mathrm{H}), 7.85-7.91(\mathrm{~m}, 3 \mathrm{H})$, 7.98-8.08 (m, 4H), $8.16(\mathrm{dd}, J=2.2$ and $9.3 \mathrm{~Hz}, 1 \mathrm{H})$; ${ }^{13} \mathrm{C} \mathrm{NMR}$ (75 MHz, $\mathrm{CDCl}_{3}$; two rotamers): $\delta=173.2,173.1$, $172.4,172.2,155.1,154.5,136.6,135.8,135.6,131.8,131.2$, $130.4,129.1,129.0,128.8,128.7,128.6,128.5,128.4,128.3$, $127.9,127.8,127.2,126.3,125.5,125.3,125.2,123.6,72.9$, 
Table 12. Selected ${ }^{1} \mathrm{H}$ NMR spectroscopic data for diastereoisomers and HPLC data for enantiomers of compounds obtained in the reactions between cyclohexanone and aryl aldehydes.

\begin{tabular}{|c|c|c|c|c|c|c|c|c|c|}
\hline & \multirow{2}{*}{ Compound } & \multicolumn{2}{|c|}{${ }^{1} \mathrm{H}$ NMR $\left(\mathrm{CDCl}_{3}\right)$} & \multicolumn{6}{|c|}{ HPLC } \\
\hline & & $\begin{array}{l}\text { syn } 1^{\prime} \mathrm{H} \\
{[\mathrm{ppm}]}\end{array}$ & $\begin{array}{l}\text { anti } 1^{\prime} \mathrm{H} \\
{[\mathrm{ppm}]}\end{array}$ & Column & $\begin{array}{l}\text { Eluent [hexane/i- } \\
\text { PrOH] }\end{array}$ & $\begin{array}{l}\text { Flow } \\
{\left[\mathrm{mL} \mathrm{min}^{-1}\right]}\end{array}$ & $\begin{array}{l}\lambda \\
{[\mathrm{nm}]}\end{array}$ & $\begin{array}{l}\mathrm{t}_{\mathrm{R}} \text { Major } \\
{[\mathrm{min}]}\end{array}$ & $\begin{array}{l}\mathrm{t}_{\mathrm{R}} \text { Minor } \\
{[\mathrm{min}]}\end{array}$ \\
\hline $1^{[a, b]}$ & & 5.4 & 4.8 & AS-H & $90: 10$ & 0.5 & 238 & 26.7 & 29.6 \\
\hline $2^{[a, b, c]}$ & & 5.4 & 4.8 & AS-H & $90: 10$ & 1.0 & 254 & 33.8 & 29.9 \\
\hline $3^{[a, b, d]}$ & & 5.5 & 4.9 & AS-H & $90: 10$ & 0.5 & 217 & 28.4 & 30.2 \\
\hline $4^{[a, b]}$ & & 5.6 & 5.0 & AS-H & $90: 10$ & 0.5 & 230 & 86.8 & 75.2 \\
\hline $5^{[a, c]}$ & & 5.3 & 4.8 & OD-H & $95: 5$ & 0.5 & 217 & 12.4 & 15.9 \\
\hline $6^{[a, b]}$ & & 5.4 & 4.8 & AS-H & $90: 10$ & 0.5 & 219 & 14.3 & 23.1 \\
\hline $7^{[\mathrm{a}, \mathrm{e}]}$ & & 5.7 & 5.3 & OD-H & $95: 5$ & 1.0 & 212 & 10.1 & 13.5 \\
\hline $8^{[\mathrm{f}]}$ & & 5.3 & 4.7 & AS-H & $90: 10$ & 1.0 & 254 & 15.9 & 20.7 \\
\hline $9^{[a, g]}$ & & 5.5 & 4.8 & AS-H & $98: 2$ & 1.0 & 245 & 53.5 & 65.1 \\
\hline $10^{[\mathrm{a}]}$ & & 5.4 & 4.9 & OD-H & $90: 10$ & 1.0 & 210 & 35.9 & 32.1 \\
\hline 11 & & 5.4 & 4.9 & AD-H & $90: 10$ & 1.0 & 254 & 30.5 & 33.0 \\
\hline
\end{tabular}
[a] Ref. $^{[18 \mathrm{e}]}$
[b] Ref. ${ }^{[5]}$
[c] $\operatorname{Ref}^{[23]}$
[d] Ref. ${ }^{[12]}$
[e] $\operatorname{Ref}^{[4 c]}$
[f] $\operatorname{Ref}^{[18 h]}$
[g] Ref. ${ }^{[6]}$ 
Table 13. Selected ${ }^{1} \mathrm{H}$ NMR spectroscopic data for diastereoisomers and HPLC data for enantiomers of compounds obtained in the reactions between cyclopentanone and aryl aldehydes.

\begin{tabular}{|c|c|c|c|c|c|c|c|c|c|}
\hline & \multirow[t]{2}{*}{ Compound } & \multicolumn{2}{|c|}{${ }^{1} \mathrm{H}$ NMR $\left(\mathrm{DMSO}-d_{6}\right)$} & \multicolumn{6}{|c|}{ HPLC } \\
\hline & & $\begin{array}{l}\text { syn } 1^{\prime} \mathrm{H} \\
{[\mathrm{ppm}]}\end{array}$ & $\begin{array}{l}\text { anti } 1^{\prime} \mathrm{H} \\
{[\mathrm{ppm}]}\end{array}$ & Column & $\begin{array}{l}\text { Eluent [hexane } / i- \\
\text { PrOH] }\end{array}$ & $\begin{array}{l}\text { Flow } \\
{\left[\mathrm{mL} \min ^{-1}\right]}\end{array}$ & $\begin{array}{l}\lambda \\
{[\mathrm{nm}]}\end{array}$ & $\begin{array}{l}t_{R} \text { Major } \\
{[\mathrm{min}]}\end{array}$ & $\begin{array}{l}t_{R} \text { Minor } \\
{[\mathrm{min}]}\end{array}$ \\
\hline $1^{[a, b]}$ & & 5.1 & 5.0 & OD-H & $90: 10$ & 1.0 & 213 & 11.6 & 14.0 \\
\hline $2^{[a, b, c]}$ & & 5.4 & 4.8 & AD-H & $90: 10$ & 0.5 & 265 & 113.1 & 109.7 \\
\hline $3^{[\mathrm{d}]}$ & & 5.3 & 5.1 & AD-H & $95: 5$ & 1.0 & 269 & 41.9 & 62.9 \\
\hline $4^{[\mathrm{e}]}$ & & 5.7 & 5.2 & OD-H & $95: 5$ & 1.0 & 254 & 28.6 & 32.3 \\
\hline $4^{[\mathrm{f}]}$ & & 5.1 & 5.0 & $\mathrm{AD}-\mathrm{H}$ & $95: 5$ & 1.0 & 220 & 27.9 & 30.3 \\
\hline $5^{[\mathrm{c}, \mathrm{g}]}$ & & 5.2 & 4.7 & OD-H & $90: 10$ & 0.5 & 231 & 113.7 & 98.5 \\
\hline $6^{[\mathrm{h}]}$ & & 5.1 & 5.2 & AD-H & $90: 10$ & 1.0 & 214 & 12.3 & 16.9 \\
\hline $7^{[\mathrm{i}]}$ & & 5.1 & 5.0 & AD-H & $95: 5$ & 1.0 & 213 & 16.7 & 17.9 \\
\hline $8^{[\mathrm{j}]}$ & & 5.1 & 5.4 & AD-H & $98: 2$ & 1.0 & 220 & 28.2 & 37.8 \\
\hline 9 & & 5.0 & 4.9 & AD-H & $90: 10$ & 0.5 & 270 & 34.9 & 37.0 \\
\hline $10^{[\mathrm{k}]}$ & & 5.1 & 4.9 & AD-H & $90: 10$ & 0.5 & 220 & 28.3 & 32.3 \\
\hline $11^{[1]}$ & & 5.3 & 5.2 & AD-H & $95: 5$ & 1.0 & 264 & 36.4 & 40.1 \\
\hline
\end{tabular}

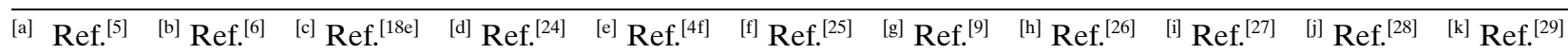
${ }^{[1]} \operatorname{Ref}^{[8]}$

$72.2,67.7,67.4,58.4,58.1,53.0,53.1,52.6,37.0,36.0,34.1$, 33.0, 31.3, 26.9; IR (liquid film): $\tilde{v}_{\max }=1738,1713 \mathrm{~cm}^{-1}$; anal. calcd. for $\mathrm{C}_{40} \mathrm{H}_{35} \mathrm{NO}_{6}$ (625.71): $\mathrm{C}$ 76.78, $\mathrm{H}$ 5.64, $\mathrm{N}$ 2.24; found: C 76.77, H 5.67, N 2.26.

\section{General Procedure for the Synthesis of Compounds 1a-e}

To a solution of compounds 4 (1.91 mmol) in methanol $(65 \mathrm{~mL}) \mathrm{Pd}(10 \%) / \mathrm{C}(308 \mathrm{mg})$ was added. The reaction mix- 


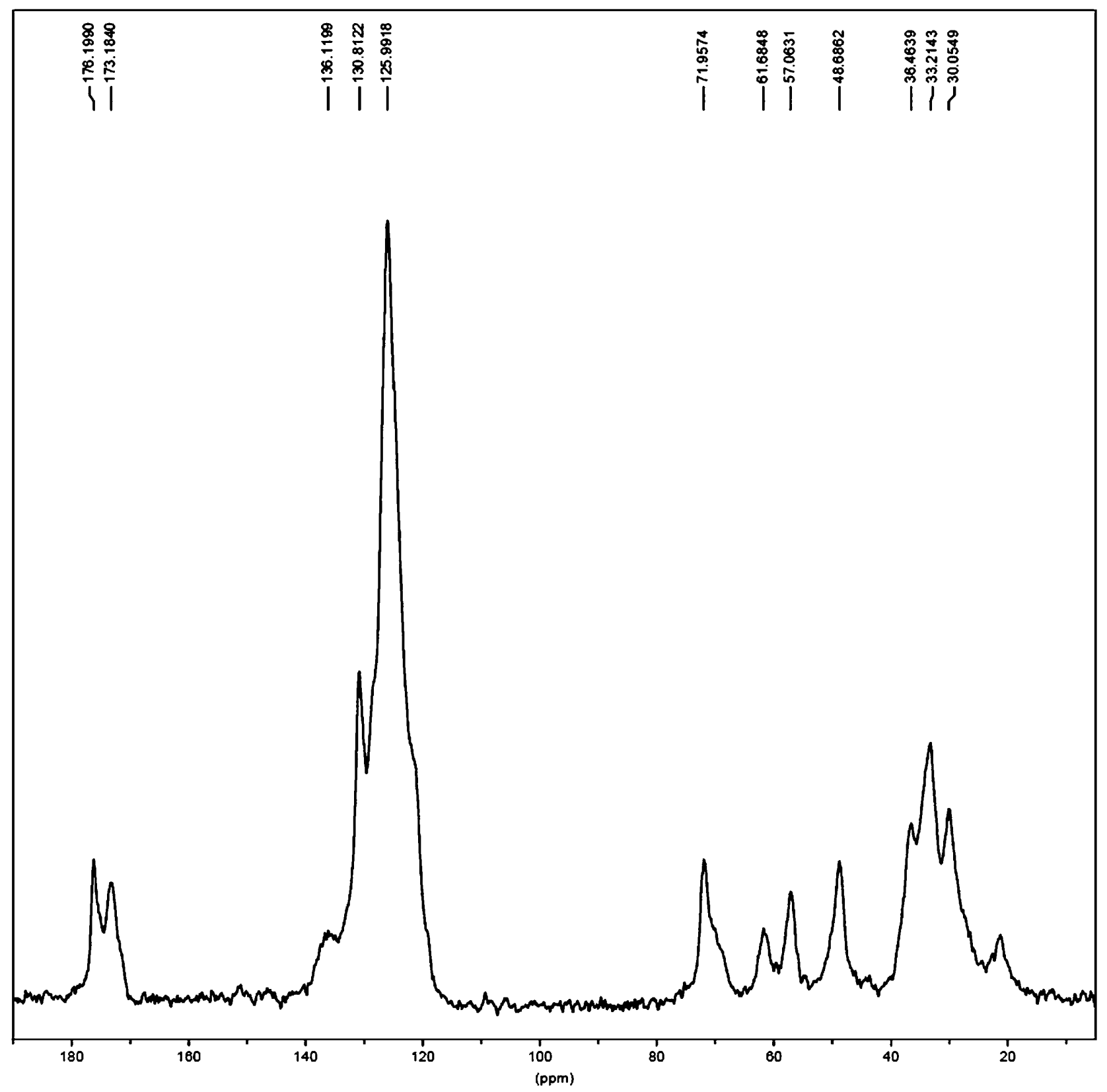

Figure 8. Solid state ${ }^{13} \mathrm{C}$ NMR of compound $\mathbf{1 e}$.

ture was stirred under hydrogen in a Parr apparatus for $3 \mathrm{~h}$. After this time the reaction mixture was filtered through a short pad of Celite and then through a short pad of silica, washing with methanol. The organic phase was concentrated under reduced pressure to give compounds 1a-e.

(2S,4R)-4-(Benzoyloxy)pyrrolidine-2-carboxylic acid (1a): Pale yellow solid; yield: $96 \%$; $[\alpha]_{\mathrm{D}}^{27}$ : $-4.6\left(c 0.32, \mathrm{CHCl}_{3}\right)$; mp $180-185^{\circ} \mathrm{C} .{ }^{1} \mathrm{H}$ NMR (DMSO- $d_{6}$ ): $\delta=2.08$ (ddd, $J=4.8$, 9.6 and $14.4 \mathrm{~Hz}, 1 \mathrm{H}$ ), 2.24 (ddd, $J=7.8,7.8$ and $14.4 \mathrm{~Hz}$, $1 \mathrm{H}), 3.22(\mathrm{~d}, J=13.0 \mathrm{~Hz}, 1 \mathrm{H}), 3.41(\mathrm{dd}, J=4.4$ and $13.0 \mathrm{~Hz}$, $1 \mathrm{H}), 3.85(\mathrm{dd}, J=9.4$ and $9.4 \mathrm{~Hz}, 1 \mathrm{H}), 5.34-5.38(\mathrm{~m}, 1 \mathrm{H})$, 7.41-7.46 (m, 2H), 7.54-7.60 (m, 1H), 7.91-7.95 (m, 2H); ${ }^{13} \mathrm{C} \mathrm{NMR}\left(\mathrm{CDCl}_{3}\right): \delta=173.7,165.5,133.2,129.7,129.3$, 128.3, 73.9, 60.4, 50.6, 35.5; IR (nujol): $\tilde{v}_{\max }=3500-2600$ (broad $\mathrm{COOH}$ ), $1717 \mathrm{~cm}^{-1}$; anal. calcd. for $\mathrm{C}_{12} \mathrm{H}_{13} \mathrm{NO}_{4}$ (235.24): C 61.27, H 5.57, N 5.95; found: C 61.22, H 5.52, N 5.99 .

(2S,4R)-4-(2-Phenylacetoxy)pyrrolidine-2-carboxylic acid (1b): Highly viscous oil; yield: $95 \% ;[\alpha]_{\mathrm{D}}^{25}:-5.2(c) 0.84$, $\left.\mathrm{CHCl}_{3}\right) .{ }^{1} \mathrm{H} \mathrm{NMR}\left(\mathrm{CDCl}_{3}\right): \delta=2.08-2.30(\mathrm{~m}, 2 \mathrm{H}), 3.12(\mathrm{~d}$, $J=12.9 \mathrm{~Hz}, 1 \mathrm{H}), 3.50-3.65(\mathrm{~m}, 3 \mathrm{H}), 4.01(\mathrm{dd}, J=7.8$ and $10.5 \mathrm{~Hz}, 1 \mathrm{H}), 5.17-5.21(\mathrm{~m}, 1 \mathrm{H}), 7.13-7.26(\mathrm{~m}, 5 \mathrm{H}), 7.95$ (br s, $\mathrm{OH}) ;{ }^{13} \mathrm{C}$ NMR $\left(75 \mathrm{MHz}, \mathrm{CDCl}_{3}\right): \delta=173.9,171.0,133.7$, 129.6, 129.1, 127.6, 74.0, 60.9, 50.6, 41.4, 35.8; IR (liquid film): $\tilde{v}_{\max }=3500-2600$ (broad $\mathrm{COOH}$ ), $1720 \mathrm{~cm}^{-1}$; anal. calcd. for $\mathrm{C}_{13} \mathrm{H}_{15} \mathrm{NO}_{4}$ (249.26): $\mathrm{C}$ 62.64, $\mathrm{H}$ 6.07, $\mathrm{N}$ 5.62; found: C 62.67, H 6.04, N 5.60. 
(2S,4R)-4-(3-Phenylpropanoyloxy)pyrrolidine-2-carboxylic acid (1c): White-gray powder after recrystalizatiom from hexane/dichloromethane; yield: $96 \%$; $[\alpha]_{\mathrm{D}}^{27}$ : -19.8 (c 0.49 , $\mathrm{CH}_{3} \mathrm{OH}$ ); $\mathrm{mp} 202-206{ }^{\circ} \mathrm{C}$. ${ }^{1} \mathrm{H}$ NMR $\left(\mathrm{CD}_{3} \mathrm{OD}\right): \delta=2.20$ (ddd, $J=4.9,10.2$ and $14.9 \mathrm{~Hz}, 1 \mathrm{H}$ ), 2.40 (dddd, $J=1.5,1.5,7.8$ and $14.9 \mathrm{~Hz}, 1 \mathrm{H}), 2.61-2.67(\mathrm{~m}, 2 \mathrm{H}), 2.90(\mathrm{t}, J=7.6 \mathrm{~Hz}$ $2 \mathrm{H}), 3.26-3.31(\mathrm{~m}, 1 \mathrm{H}), 3.54(\mathrm{dd}, J=4.5$ and $13.1 \mathrm{~Hz}, 1 \mathrm{H})$, $4.06(\mathrm{dd}, J=8.0$ and $10.2 \mathrm{~Hz}, 1 \mathrm{H}), 5.30-5.35(\mathrm{~m}, 1 \mathrm{H}), 7.10$ $7.28(\mathrm{~m}, 5 \mathrm{H}) ;{ }^{13} \mathrm{C} \mathrm{NMR}\left(75 \mathrm{MHz}, \mathrm{CD}_{3} \mathrm{OD}\right): \delta=173.5,173.0$, $141.7,129.6,129.3,127.4,74.8,61.5,51.8,36.6,36.5,31.7$; IR (nujol): $\tilde{v}_{\max }=3500-2600$ (broad $\left.\mathrm{COOH}\right), 1733 \mathrm{~cm}^{-1}$; anal. calcd. for $\mathrm{C}_{14} \mathrm{H}_{17} \mathrm{NO}_{4}$ (263.29): C 63.87, H 6.51, N 5.32; found: C 63.91, H 6.48, N 5.30.

(2S,4R)-4-(4-Phenylbutanoyloxy)pyrrolidine-2-carboxylic acid (1d): Pale orange solid after purification by column chromatography (petroleum ether/ethyl acetate, 4:1; yield: $78 \%$; $[\alpha]_{\mathrm{D}}^{31}:-3.02\left(\right.$ c $\left.0.52, \mathrm{CHCl}_{3}\right) ; \mathrm{mp} 129-133^{\circ} \mathrm{C} .{ }^{1} \mathrm{H}$ NMR $\left(\mathrm{CDCl}_{3}\right): \delta=1.84-2.01(\mathrm{~m}, 2 \mathrm{H}), 2.20-2.46(\mathrm{~m}, 4 \mathrm{H}), 2.66(\mathrm{t}$, $J=7.5 \mathrm{~Hz}, 1 \mathrm{H}), 3.20-3.27(\mathrm{~m}, 1 \mathrm{H}), 3.70-3.80(\mathrm{~m}, 1 \mathrm{H}), 4.12$ $(\mathrm{dd}, J=9.6$ and $9.6 \mathrm{~Hz}, 1 \mathrm{H}), 5.27-5.33(\mathrm{~m}, 1 \mathrm{H}), 7.16-7.35$ $(\mathrm{m}, 5 \mathrm{H}) ;{ }^{13} \mathrm{C} \mathrm{NMR}\left(\mathrm{CDCl}_{3}\right): \delta=173.9,173.1,141.5,128.9$, $128.8,126.5,73.4,60.9,50.7,35.8,35.4,33.8,26.6$; IR (nujol): $\tilde{v}_{\max }=3500-2600$ (broad COOH), $1732 \mathrm{~cm}^{-1}$; anal. calcd. for $\mathrm{C}_{15} \mathrm{H}_{19} \mathrm{NO}_{4}$ (277.32): C 64.97, H 6.91, N 5.05; found: C 65.06, H 6.93, N 5.10.

(2S,4R)-4-[4-(Pyren-1-yl)butanoyloxy]pyrrolidine-2-carboxylic acid (1e): This product was recovered after washing the silica pad with hot methanol and toluene as a white-gray powder; yield: $95 \%$; $\mathrm{mp} 206-210^{\circ} \mathrm{C}$. Since this compound is very poorly soluble, it was characterized by solid state ${ }^{13} \mathrm{C} \mathrm{NMR}$ (Figure 8); IR (nujol): $\tilde{v}_{\max }=2900$ (broad, $\mathrm{COOH}$ ), $1731 \mathrm{~cm}^{-1}$; anal. calcd. for $\mathrm{C}_{25} \mathrm{H}_{23} \mathrm{NO}_{4}$ (401.45): $\mathrm{C}$ 74.79, H 5.77, N 3.49; found: C 74.77, H 5.73, N 3.41.

\section{Typical Procedure for Aldol Reaction}

Catalyst $\mathbf{1}(0.01 \mathrm{mmol})$ was added to a mixture of the corresponding aldehyde $(0.5 \mathrm{mmol})$ and ketone $(2.5 \mathrm{mmol})$ in distilled water $(0.175 \mathrm{~mL})$, and the reaction mixture was stirred at room temperature. The reaction was quenched by adding ethyl acetate and the organic phase washed with water. The organic layer was dried $\left(\mathrm{MgSO}_{4}\right)$ and concentrated under reduced pressure. The crude product was checked by ${ }^{1} \mathrm{H}$ NMR spectroscopy and HPLC, and was then purified by chromatography (petroleum ether/ethyl acetate).

$(S)-2-[(R)$-hydroxy(3-methoxyphenyl)methyl $]$ cyclopentanone: Pale yellow viscous oil after purification by column chromatography (petroleum ether/ethyl acetate, 6:1-3:1); mixture of diastereoisomers. ${ }^{1} \mathrm{H}$ NMR $\left(\mathrm{CDCl}_{3}\right): \delta=1.58$ $2.58(\mathrm{~m}, 6 \mathrm{H}$, anti + syn $), 2.80-2.83(\mathrm{~m}, 1 \mathrm{H}$, syn $), 3.91(\mathrm{~s}, 3 \mathrm{H}$, anti+syn $), 4.66(\mathrm{~s}, 1 \mathrm{H}, \mathrm{OH}$, anti + syn $), 4.79(\mathrm{~d}, J=9.0 \mathrm{~Hz}$, $1 \mathrm{H}$, anti), 5.36-5.38 (m, 1 H, syn), 6.88-7.02 (m, 3 H, anti + syn), 7.32-7.38 (m, 1 H, anti +syn $) ;{ }^{13} \mathrm{C} \mathrm{NMR}\left(\mathrm{CDCl}_{3}\right.$; anti diastereoisomer): $\delta=223.0,159.6,143.0,129.3,118.9,113.4$, 111.8, 75.0, 55.2, 55.1, 38.7, 26.9, 20.3; (syn diastereoisomer): $\delta=220.3,159.5,144.6,126.3,117.7,112.5,111.1,71.2,56.0$, 55.1, 39.1, 22.6, 20.4; IR (liquid film): $\tilde{v}_{\max }=3447,1724 \mathrm{~cm}^{-1}$; anal. calcd. for $\mathrm{C}_{14} \mathrm{H}_{17} \mathrm{NO}_{4}$ (263.29): C 70.89, H 7.32; found: C 70.91, H 7.35.

\section{Acknowledgements}

Financial support from the University of Palermo (Funds for selected topics) and the Italian MIUR within the National Project "Catalizzatori, metodologie e processi innovativi per il regio- e stereocontrollo delle sintesi organiche” and the "Centro Grandi Apparecchiature - UniNetLab - Università di Palermo funded by P.O.R. Sicilia 2000-2006, Misura 3.15 Quota Regionale” ${ }^{13} \mathrm{C}\left\{{ }^{1} \mathrm{H}\right\} \mathrm{CP}-\mathrm{MAS}$ spectrum) are gratefully acknowledged.

\section{References}

[1] S. Mukherjee, J. W. Yang, S. Hoffman, B. List, Chem. Rev. 2007, 107, 5471-5569.

[2] a) Z. G. Hajos, D. R. Parrish, German Patent 2102 623, 1971; b) Z. G. Hajos, D. R. Parrish, J. Org. Chem. 1974, 39, 1615-1621; c) U. Eder, G. Sauer, R. Wiechert, German Patent 2014 757, 1971; d) U. Eder, G. Sauer, R. Wiechert, Angew. Chem. Int. Ed. Engl. 1971, 10, 496-497; e) B. List, R. A. Lerner, C. F. Barbas III, J. Am. Chem. Soc. 2000, 122, 2395-2396.

[3] K. Sakthivel, W. Notz, T. Bui, C. F. Barbas III, J. Am. Chem. Soc. 2001, 123, 5260-5267.

[4] a) Z. Tang, F. Jiang, L.-T. Yu, X. Cui, L.-Z. Gong, A.Q. Mi, Y.-Z. Jiang, Y.-D. Wu, J. Am. Chem. Soc. 2003, 125, 5262-5263; b) Z. Tang, F. Jiang, X. Cui, L.-Z. Gong, A.-Q. Mi, Y.-Z. Jiang, Y.-D. Wu, Proc. Natl. Acad. Sci. USA 2004, 101, 5755-5760; c) J.-R. Chen, H.-H. Lu, X.-Y. Li, L. Cheng, J. Wan, W.-J. Xiao, Org. Lett. 2005, 7, 4543-4545; d) S. Samanta, J. Liu, R. Dodda, C.-G. Zhao, Org. Lett. 2005, 7, 5321-5323; e) J.-R. Chen, X.-Y. Li, X.-N. Xing, W. J. Xiao, J. Org. Chem. 2006, 71, 8198-8202; f) Y.-Q. Fu, Z.-C. Li, L.-N. Ding, J.-C. Tao, S.-H. Zhang, M.-S. Tang, Tetrahedron: Asymmetry 2006, 17, 3351-3357; g) M. Raj, V. Maya, S. K. Ginotra, V. K. Singh, Org. Lett. 2006, 8, 40974099; h) G. Guillena, M. C. Hita, C. Nájera, ARKIVOC 2007, 260-269; i) A. Russo, G. Botta, A. Lattanzi, Tetrahedron 2007, 63, 11886-11892; j) X.-Y. Xu, Y.-Z. Wang, L.-Z. Gong, Org. Lett. 2007, 9, 4247-4249; k) S. Sathapornvajana, T. Vilaivan, Tetrahedron 2007, 63, 10253-10259; 1) J.-R. Chen, X.-L. An, X.-Y. Zhu, X.-F. Wang, W.-J. Xiao, J. Org. Chem. 2008, 73, 6006-6009.

[5] N. Mase, Y. Nakai, N. Ohara, H. Yoda, K. Takabe, F. Tanaka, C. F. Barbas III, J. Am. Chem. Soc. 2006, 128, 734-735.

[6] Y. Hayashi, T. Sumiya, J. Takahashi, H. Gotoh, T. Urushima, M. Shoji, Angew. Chem. Int. Ed. 2006, 45, 958961.

[7] T. J. Dickerson, K. D. Janda, J. Am. Chem. Soc. 2002, 124, 3220-3221.

[8] Y.-W. Wu, Y. Chen, D.-S. Deng, J. Cai, Synlett 2005, $1627-1629$.

[9] Z. Jiang, Z. Liang, X. Wu, Y. Lu, Chem. Commun. 2006, 2801-2803.

[10] M. Amedjkouh, Tetrahedron: Asymmetry 2007, 18, 390-395.

[11] P. Dziedzic, W. Zou, J. Háfren, A. Córdova, Org. Biomol. Chem. 2006, 4, 38-40. 
[12] M. Lei, L. Shi, G. Li, S. Chen, W. Fang, Z. Ge, T. Cheng, R. Li, Tetrahedron 2007, 63, 7892-7898.

[13] Type II: a) S. S. Chimni, D. Mahajan, Tetrahedron: Asymmetry 2006, 17, 2108-2119; b) Y. Wu, Y. Zhang, M. Yu, G. Zhao, S. Wang, Org. Lett. 2006, 8, 44174420 ; c) S. Guizzetti, M. Benaglia, L. Raimondi, G. Celentano, Org. Lett. 2007, 9, 1247-1250; d) V. Maya, M. Raj, V. K. Singh, Org. Lett. 2007, 9, 2593-2595; e) W.P. Huang, J.-R. Chen, X.-Y. Li, Y.-J. Cao, W.-J. Xiao, Can. J. Chem. 2007, 85, 211-216; f) D. Gryko, W. J. Saletra, Org. Biomol. Chem. 2007, 5, 2148-2153; g) C. Wang, Y. Jiang, X.-x. Zhang, Y. Huang, B.-g. Li, G.-1. Zhang, Tetrahedron Lett. 2007, 48, 4281-4285; h) L. $\mathrm{Zu}$, H. Xie, H. Li, J. Wang, W. Wang, Org. Lett. 2008, 10, 1211-1214. Type III: i) L. Zhong, Q. Gao, J. Gao, J. Xiao, C. Li, J. Catal. 2007, 250, 360-364; j) Y.-Q. Fu, Y.-J. An, W.-M. Liu, Z.-C. Li, G. Zhang, J.-C. Tao, Catal. Lett. 2008, 124, 397-404; k) S. Aratake, T. Itoh, T. Okano, N. Nagae, T. Sumiya, M. Shoji, Y. Hayashi, Chem. Eur. J. 2007, 13, 10246-10256; Type IV: 1) J.-F. Zhao, L. He, J. Jiang, L.-F. Cun, L.-Z. Gong, Tetrahedron Lett. 2008, 49, 3372-3375.

[14] a) X. Wu, Z. Jiang, H.-M. Shen, Y. Lu, Adv. Synth. Catal. 2007, 349, 812-816; b) M.-K. Zhu, X.-Y. Xu, L.Z. Gong, Adv. Synth. Catal. 2008, 350, 1390-1396; c) F.-Z. Peng, Z.-H- Shao, X.-W. Pu, H.-B. Zhang, Adv. Synth. Catal. 2008, 350, 2199-2204.

[15] A. P. Brogan, T. J. Dickerson, K. D. Janda, Angew. Chem. Int. Ed. 2006, 45, 8100-8102.

[16] Y. Hayashi, Angew. Chem. Int. Ed. 2006, 45, 81038104.

[17] D. G. Blackmond, A. Armstrong, V. Coombe, A. Wells, Angew. Chem. Int. Ed. 2007, 46, 3798-3800.

[18] a) M. Gruttadauria, F. Giacalone, R. Noto, Chem. Soc. Rev. 2008, 37, 1666-1688; b) M. Gruttadauria, S. Riela, P. Lo Meo, F. D'Anna, R. Noto, Tetrahedron Lett. 2004, 45, 6113-6116; c) M. Gruttadauria, S. Riela, C. Aprile,
P. Lo Meo, F. D'Anna, R. Noto, Adv. Synth. Catal. 2006, 348, 82-92; d) F. Giacalone, M. Gruttadauria, A. Mossuto Marculescu, R. Noto, Tetrahedron Lett. 2007, 48, 255-259; e) M. Gruttadauria, F. Giacalone, A. Mossuto Marculescu, S. Riela, R. Noto, Eur. J. Org. Chem. 2007, 4688-4698; f) C. Aprile, F. Giacalone, M. Gruttadauria, A. Mossuto Marculescu, R. Noto, J. D. Revell, H. Wennemers, Green Chem. 2007, 9, 1328-1334; g) F. Giacalone, M. Gruttadauria, A. Mossuto Marculescu, F. D'Anna, R. Noto, Catal. Commun. 2008, 9, 14771481; h) M. Gruttadauria, F. Giacalone, A. Mossuto Marculescu, R. Noto, Adv. Synth. Catal. 2008, 350, 1397-1405.

[19] M. Gruttadauria, F. Giacalone, P. Lo Meo, A. Mossuto Marculescu, S. Riela, R. Noto, Eur. J. Org. Chem. 2008, 1589-1596.

[20] Y. Jung, R. A. Marcus, J. Am. Chem. Soc. 2007, 129, $5492-5502$

[21] S. Bahmanyar, K. N. Houk, H. J. Martin, B. List, J. Am. Chem. Soc. 2003, 125, 2475-2479.

[22] J. K. Robinson, V. Lee, T. D. W. Claridge, J. E. Baldwin, C. J. Schofield, Tetrahedron 1998, 54, 981-996.

[23] A. Yanagisawa, H. Takahashi, T. Arai, Chem. Commun. 2004, 580-581.

[24] B. Rodríguez, A. Bruckmann, C. Bolm, Chem. Eur. J. 2007, 13, 4710-4722.

[25] D.-S. Deng, J. Cai, Helv. Chim. Acta 2007, 90, 114-120.

[26] a) P. Kotrusz, I. Kmentová, B. Gotov, Ŝ. Toma, E. Solcániová, Chem. Commun. 2002, 2510-2511; b) M. Nakajima, T. Yokota, M. Saito, S. Hashimoto, Tetrahedron Lett. 2004, 45, 61-64.

[27] G. L. Puleo, A. Iuliano, Tetrahedron: Asymmetry 2007, 18, 2894-2900.

[28] Y. Hayashi, S. Aratake, T. Itoh, T. Okano, T. Sumiya, M. Shoji, Chem. Commun. 2007, 957-959.

[29] Y.-Y. Peng, H. Liu, M. Cui, J.-P. Cheng, Chin. J. Chem. 2007, 25, 962-967. 